\title{
Screening for GJB2-R143W-Associated Hearing Impairment: Implications for Health Policy and Practice in Ghana
}

\author{
Samuel M. Adadey ${ }^{a, b}$ Osbourne Quaye ${ }^{a}$ Geoffrey K. Amedofu ${ }^{c}$ \\ Gordon A. Awandare ${ }^{a}$ Ambroise Wonkam ${ }^{b}$ \\ aWest African Centre for Cell Biology of Infectious Pathogens (WACCBIP), University of Ghana, Accra, Ghana; \\ bivision of Human Genetics, Faculty of Health Sciences, University of Cape Town, Cape Town, South Africa; \\ 'Department of Eye Ear Nose \& Throat, School of Medical Sciences, Kwame Nkrumah University of Science and \\ Technology, Kumasi, Ghana
}

\section{Key Messages}

1. GJB2-R143W founder mutation is the major cause associated with $\mathrm{HI}$ in Ghana, with a relatively high population carrier frequency of $1.45 \%$ amongst healthy Ghanaians.

2. GJB2-R143W accounts for nearly $26 \%$ of causes in families segregating congenital non-syndromic HI.

3. There is a rapid test designed for screening for the GJB2-R143W variant. We recommend that this test be adopted as part of the universal newborn hearing screening (UNHS) program in Ghana.

4. Early testing for the GJB2-R143W variant could lead to early detection of HI and the provision of medical and social services that will help improve the quality of life of affected individuals.

5. Cochlear implant should be developed in Ghana as the method of choice for correcting HI in children diagnosed before the age of language development.

\section{Keywords}

Health policy · GJB2-R143W founder mutation · Hearing impairment · Newborn screening · Ghana

\section{Abstract \\ Genetic factors significantly contribute to the burden of hearing impairment $(\mathrm{HI})$ in Ghana as there is a high carrier frequency $(1.5 \%)$ of the connexin 26 gene founder variant GJB2-R143W in the healthy Ghanaian population. GJB2- R143W mutation accounts for nearly $26 \%$ of causes in fami- lies segregating congenital non-syndromic $\mathrm{HI}$. With $\mathrm{HI}$ asso- ciated with high genetic fitness, this indicates that Ghana}

karger@karger.com www.karger.com/phg

Karger

GOPEN ACCESS
(C) 2020 The Author(s)

Published by S. Karger AG, Basel

This article is licensed under the Creative Commons Attribution 4.0 International License (CC BY) (http://www.karger.com/Services/ OpenAccessLicense). Usage, derivative works and distribution are permitted provided that proper credit is given to the author and the original publisher. will likely sustain an increase in the number of individuals living with inheritable $\mathrm{HI}$. There is a universal newborn hearing screening (UNHS) program in Ghana. However, this program does not include genetic testing. Adding genetic testing of GJB2-R143W mutation for the population, prenatal and neonatal stages may lead to guiding genetic counseling for individual and couples, early detection of $\mathrm{HI}$ for at-risk infants, and improvement of medical management, including speech therapy and audiologic intervention, as well as provision of the needed social service to enhance parenting and education for children with $\mathrm{HI}$. Based on published research on the genetics of $\mathrm{HI}$ in Ghana, we recommend that the UNHS program should include genetic screening for the 
GJB2-R143W gene variant for newborns who did not pass the initial UNHS tests. This will require an upgrade and resourcing of public health infrastructures to implement the rapid and cost-effective GJB2-R143W testing, followed by appropriate genetic and anticipatory guidance for medical care.

(C) 2020 The Author(s)

Published by S. Karger AG, Basel

\section{Background}

Hearing impairment $(\mathrm{HI})$ is the partial or complete loss of hearing in an individual. Globally, about 1-2 of every 1,000 persons present with some form of HI [1]. In Africa, approximately 6 out of every 1,000 live births will have HI [2]. The global prevalence is expected to increase to about 900 million by 2050 [3]. Persons with HI cannot hear sound within the "normal" audible range of hearing [4], and this impacts their ability to effectively communicate with people around them. It could also affect their quality of life, including access to education, health care, and other basic social services $[5,6]$.

A common form of $\mathrm{HI}$ is non-syndromic hearing impairment (NSHI). NSHI is not associated with any known clinical symptoms [7] and presents in different forms and degrees of severity ranging from hearing loss in 1 or both ears to difficulties in understanding soft speech and inability to hear very loud noises. In some cases, the degree of hearing loss may become worse with age. NSHI could be caused by a variety of factors, some of which may be genetic or environmental [8]. The genetic causes are mainly associated with the connexin 26 gene (GJB2) mutation which is mostly inherited in an autosomal recessive pattern [9], while environmental causes include, but not limited to, exposure to loud sound, infectious diseases, and certain health conditions. In Ghana, meningitis is the main environmental cause of childhood $\mathrm{HI}$, while the main genetic cause is the inheritance of the GJB2-R143W variant [10-13].

Ghana is an English speaking West African country with an estimated population of about $30,280,482$ people [14]. About 50 and $15 \%$ of rural and urban dwellers in Ghana are living in poverty [15]. To reduce poverty, the government of Ghana has made commitments towards expanding and ensuring free access to formal education [16-18]. In spite of these efforts, an educational performance gap exists between students in urban schools and rural schools, which is possibly as a result of an uneven distribution of educational facilities and resources [19]. Similarly, schools for the deaf are mostly underprivileged and have inadequate resources for effective teaching and

Policy Statement on GJB2-R143W

Newborn Testing in Ghana learning. Hence, hearing-impaired students are part of the marginalized individuals who receive minimum attention from the government [20]. The structure of the Ghanaian society does not effectively support disabilities [20], especially the negative cultural perception of hearing-impaired people [21], and this affects the participation of hearing-impaired individuals within the society. The low participation of these individuals negatively affects their psychosocial health and makes them feel inferior in many situations [20].

Access to quality health care is a fundamental human right in Ghana, but it is often inaccessible to the hearing impaired [22]. Hearing-impaired patients face major barriers such as finance, the proximity of the facilities, and lack of sign language interpreters when accessing health care in Ghana [22, 23]. A recent study among young hearing-impaired adults underscores the need for healthcare professionals to be trained to communicate using sign language [22]. There is an uneven distribution of health facilities in the country; underdeveloped communities travel many kilometers on foot to access health service in the city centers [24]. In addition to the above challenges, the majority of Ghanaian health facilities cannot effectively diagnose $\mathrm{HI}$ at an early age where interventions are most needed $[25,26]$. To date, there is no routine clinical investigation of $\mathrm{HI}$ genes in Ghana as well as cochlear implants for affected Ghanaians. There is a need therefore to have informed policy on genetic screening for $\mathrm{HI}$ in Ghanaian infants who fail universal newborn hearing tests (UNHS) and the provision of early interventions.

\section{Universal Newborn Hearing Screening}

The UNHS has been implemented in several countries [27-29] with the aim of diagnosing HI in newborn babies to give appropriate interventions, follow-up tests, or treatments to children with permanent HI [29]. The UNHS program is also referred to as early hearing detection and intervention (EHDI) program [28]. The methods used in the UNHS are non-invasive quick tests to assess the physiological status of the infant's ear and is often conducted soon after birth. The procedure for the UNHS consists of presenting soft sounds (clicks) to the ears of the baby using auto-mated auditory brainstem response or auto-mated otoacoustic emissions. The child's response to the sound presented is measured by a sensor through the scalp. Special devices with inbuilt algorithms are used to evaluate the auditory brainstem response of 
the child. In most cases, the children who did not pass the first UNHS test are scheduled for a second test and subsequently referred to a specialist when no response is obtained from the initial tests $[28,29]$.

\section{HI: A Condition of Public Health Significance in Ghana}

HI adversely affects the cognitive development of children [6], making it challenging for them to learn vocabulary, grammar, and other aspects of verbal communication $[5,6]$. This significantly impacts their education, and in some instances persons with $\mathrm{HI}$ are considered a social and economic burden to their families and community [30]. For example, over $80 \%$ of the deaf children in Ghana are born to hearing parent, and their parents, siblings, and friends struggle to communicate with them [21]. Equally, one-on-one interviews by us with some deaf children in Ghana revealed that they feel neglected and unloved by their parents. Other studies in Ghana have reported difficulties by persons with $\mathrm{HI}$ to access social services such as health care and education or to socially adapt to their communities [21, 22, 31]. This could be frustrating for both the deaf children and other people in the community.

Early diagnosis of HI could lead to the early introduction of intervention that could support speech, language, and cognitive development for deaf children [6]. Empirical studies in South Africa and the UK have demonstrated that hearing-impaired children when diagnosed early and given the appropriate intervention, especially within the first 6 months after birth, are likely to have similar cognitive and language development as hearing children of the same age-group [5, 32, 33]. However, in Ghana, the majority of hearing-impaired children are only able to have comprehensive hearing tests after the age of 6 years [12] when they would have passed the age of language development. This impacts negatively on the effectiveness of any interventions that may be introduced to improve on their quality of life.

To facilitate early detection and management of $\mathrm{HI}$ in children, several countries have introduced UNHS into their clinical programs. However, UNHS is still not available in many African countries, and many newborn screening programs tend to rely on ontological (ENT) examination to detect hearing loss in infants [5]. Unfortunately, these diagnostic procedures are not able to provide conclusive results in infants [34]. Although UNHS was introduced in Ghana in the early 1970s, this service is still largely unavailable in most health centers across the country $[25,26]$. Failure to effectively roll out the UNHS in Ghana could be due to a variety of reasons including high cost of testing, limited infrastructural capacity, and human resources to man the service.

Genetic testing may at this time be costly for populations in sub-Saharan Africa. However, we are of the opinion that we could leverage existing knowledge and genetic programs on $\mathrm{HI}$ in Ghana to introduce a cost-effective genetic test for $\mathrm{HI}$ as part of the national UNHS package. For example, it is already established that the GJB2 gene accounts for over a quarter (26\%) of familial HI cases in Ghana [12], suggesting that 1 out of every 4 hearing-impaired families in Ghana is likely to have the GJB2 gene variants. The reported carrier frequency of nearly $1.5 \%$ suggests that among every 145 Ghanaians (without HI), 2 are likely to pass on a defective GJB2 gene to their children. Therefore, genetic screening for hearing loss may identify, at an early stage, children who are likely to develop HI.

In Ghana, there is no clinical investigation for $\mathrm{HI}$ genes, especially in the UNHS program. A number of genetic sequencing platforms for $\mathrm{HI}$ are now commercially available [35]. However, their use in resource-limited countries may be practically challenging because of limited human and infrastructural capacity to support genetic sequencing as part of routine clinical processes [36-38]. Given this practical challenge, we propose that UNHS Ghana adopts and uses a rapid and effective diagnostic tool for screening for the GJB2-R143W variant [13]. This diagnostic tool was recently developed following genetic studies on $\mathrm{HI}$ in Ghana. Unlike most commercially available tools, this diagnostic test is based on the restriction fragment length polymorphism technique and therefore does not require the use of sequencing technology. The tool has the potential to identify the common genetic cause (GJB2-R143W) of HI among Ghanaians and can effectively be used as a first-line genetic testing tool. Adding genetic testing of GJB2-R143W mutation for the population, the prenatal and neonatal level may lead to guiding genetic counseling for individual and couples, early detection of $\mathrm{HI}$ for at-risk infants, and improvement of medical management, including speech therapy and audiologic intervention, as well as provision of the needed social service to enhance parenting and education for children with HI. As the UNHS will identify more children with HI, this will further the rationale to develop a cochlear implant service in Ghana as the method of choice for hearing restoration in children diagnosed before the age of language development. 


\section{Policy Recommendations}

UNHS is an important strategy for reducing the burden of HI. Although it has been introduced in Ghana, it does not incorporate yet the option for genetic $\mathrm{HI}$ testing $[39,40]$. Therefore, despite the strong evidence for the major contribution of GJB2-R143W mutations to HI, Ghanaian children are unable to receive early HI genetic diagnosis [12]. Therefore, we recommend the following:

1. Early screening of Ghanaian children for HI should be introduced in pediatric programs across the country. For this to be possible, hearing assessment centers in Ghana, as well as the existing Community-Based Health Planning and Services (CHPS) compounds, should be equipped with the necessary logistics and human resources to complement the UNHS program.

2. Children who are found to have HI from the UNHS should be tested for mutations in GJB2 and especially R143W mutation since it accounts for the majority of $\mathrm{HI}$ in Ghana. Figure 1 shows an outline of recommended for HI newborn screening program in Ghana.

3. Laboratory diagnosis services should implement the recently developed GJB2-R143W cost-effective for HI in Ghana [13]. This will relatively decrease the cost of HI genetic screening in Ghana compared to existing costs in other African countries. This is because our cost-effective screening tool was developed based on a simple and inexpensive RFLP technic to screen for the common R143W mutation which accounts for over $26 \%$ of familial HI cases in Ghana.

4. Health services should develop genetic services including genetics counseling for HI, to accompany the UNHS program.

5. Appropriate intervention programs should be planned accordingly. This will include Cochlear implant services in Ghana; this is a standard treatment for genetic HI in high resources countries such as the UK [33]. This is however not the case in Ghana. This may be due to the inability of Ghanaian health centers to properly diagnose genetic HI. With the implementation of the suggestions above, the HI children under the UNHS scheme can be well characterized and given the appropriate interventions such as provision of hearing aids, cochlear implants, speech therapy, or early language aids. Intervention programs should extend to develop social resources to enhance parenting including sign language courses for families, equipped schools for the deaf in Ghana to improve educational attainment for affected children, and wide speech-language interventions for children and families.

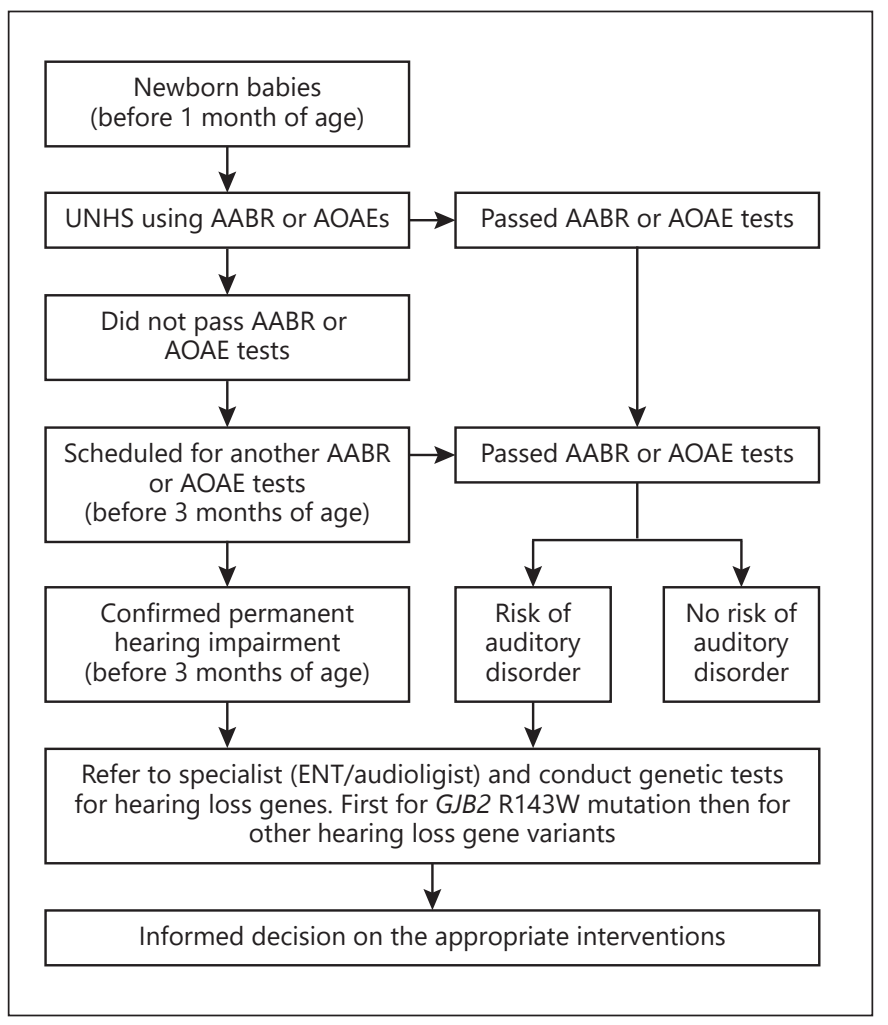

Fig. 1. Flow diagram of recommended screening process for early detection of HI in Ghana. UNHS, universal newborn hearing screening; AABR, auto-mated auditory brainstem response; AOAEs, auto-mated otoacoustic emissions; HI, hearing impairment.

\section{Conclusion}

$\mathrm{HI}$ is a noncommunicable sensory disorder of major public health concern in Ghana. The majority of congenital HI in Ghana is caused by genetic factors, of which GJB2-R143W is a major contributor. Genetic screening for GJB2-R143W in newborns in Ghana would offer families with options for timely interventions which will improve the living standards and quality of life of deaf children.

\section{Acknowledgement}

Samuel Mawuli Adadey was supported by WACCBIP DELTAS $\mathrm{PhD}$ fellowship and Africa Regional International Staff/Student Exchange (ARISE) II mobility fund. We thank Nchangwi Syntia Munung for edits and comments on several drafts of this manuscript. 


\section{Conflict of Interest Statement}

The authors declare no conflicts of interest.

\section{Funding Sources}

This work was supported by funds from the World Bank African Centres of Excellence grant (ACE02-WACCBIP: Awandare) and a Developing Excellence in Leadership, Training and Science Initiative (DELTAS) Africa grant (DEL-15-007: Awandare). The DELTAS Africa Initiative is an independent funding scheme of the African Academy of Sciences (AAS)'s Alliance for Accelerating Excellence in Science in Africa (AESA) and supported by the New Partnership for Africa's Development Planning and Coordinating Agency (NEPAD Agency) with funding from the Wellcome Trust (107755/Z/15/Z: to G.A.A. and A.W.) and the UK government; the
National Institutes of Health (NIH), USA, grant number U01HG-009716 to A.W.; and the African Academy of Science/Wellcome Trust, grant number $\mathrm{H} 3 \mathrm{~A} / 18 / 001$ to A.W. The funders had no role in the study design, data collection and analysis, decision to publish, or preparation of the manuscript.

\section{Author Contributions}

Conceptualization: A.W., G.A.A., and S.M.A.; writing - original draft preparation: S.M.A., G.A.A., and A.W.; writing - review and editing: S.M.A., O.Q., G.K.A., G.A.A., and A.W.; supervision: A.W., G.A.A., G.K.A., and O.Q.; funding acquisition: A.W. and G.A.A. All authors contributed important intellectual content presented and have read and agreed to the published version of the manuscript.

\section{References}

1 James M, Kumar P, Ninan PJ. A study on prevalence and risk factors of hearing impairment among newborns. Int J Contemp Pediatr. 2018;5(2):304-9.

2 Olusanya BO, Neumann KJ, Saunders JE. The global burden of disabling hearing impairment: a call to action. Bull World Health Organ. 2014;92(5):367-73.

3 WHO. Deafness and hearing loss. Fact sheets. Geneva, Switzerland: World Health Organization; 2019.

4 Oxenham AJ. How we hear: the perception and neural coding of sound. Annu Rev Psychol. 2018;69:27.

5 Copley G, Friderichs N. An approach to hearing loss in children. S Afr Fam Pract. 2010; 52(1):34-9.

6 Sarant JZ, Harris DC, Bennet LA. Academic outcomes for school-aged children with severe-profound hearing loss and early unilateral and bilateral cochlear implants. J Speech Lang Hear Res. 2015;58(3):1017-32.

7 Birkenhäger R, Aschendorff $\mathrm{A}$, Schipper J, Laszig R. [Non-syndromic hereditary hearing impairment]. Laryngorhinootologie. 2007; 86(4):299-3.

8 Wonkam A, Noubiap JJ, Djomou F, Fieggen K, Njock R, Toure GB. Aetiology of childhood hearing loss in Cameroon (sub-Saharan Africa). Eur J Med Genet. 2013;56(1):20-5.

9 Lebeko K, Bosch J, Noubiap JJ, Dandara C, Wonkam A. Genetics of hearing loss in Africans: use of next generation sequencing is the best way forward. Pan Afr Med J. 2015 Apr 17 20:383.

10 Brobby GW, Müller-Myhsok B, Horstmann RD. Connexin $26 \mathrm{R} 143 \mathrm{~W}$ mutation associated with recessive nonsyndromic sensorineural deafness in Africa. N Engl J Med. 1998 Feb 19;338(8):548-50.

11 Hamelmann C, Amedofu GK, Albrecht K Muntau B, Gelhaus A, Brobby GW, et al. Pattern of connexin 26 (GJB2) mutations causing sensorineural hearing impairment in Ghana. Hum Mutat. 2001;18(1):84-5.

12 Adadey SM, Manyisa N, Mnika K, De Kock C, Nembaware V, Quaye O, et al. GJB2 and GJB6 mutations in non-syndromic childhood hearing impairment in Ghana. Front Genet. 2019; 10:841-10.

13 Adadey SM, Tingang Wonkam E, Twumasi Aboagye E, Quansah D, Asante-Poku A, Quaye $\mathrm{O}$, et al. Enhancing genetic medicine: rapid and cost-effective molecular diagnosis for a GJB2 founder mutation for hearing impairment in Ghana. Genes. 2020 Jan 27;11(2):132.

14 Ghana_Statistical_Service. Demography: Population Projection. Social and Demography Demography 2009.

15 Cooke E, Hague S, McKay A. The Ghana poverty and inequality report: using the 6th Ghana living standards survey. Brighton, England: University of Sussex; 2016.

16 Adu Boahen E, Yamauchi C. The effect of female education on adolescent fertility and early marriage: evidence from free compulsory universal basic education in Ghana. J Afr Econ. 2018;27(2):227-48.

17 Ekundayo OS. The right to free and compulsory primary education in Ghana: lessons for other African countries. J Law Policy Globalization. 2018;69:105.

18 Salifu I, Boateng JK, Kunduzore SS. Achieving free compulsory universal basic education through school feeding programme: evidence from a deprived rural community in northern Ghana. Cogent Educ. 2018;5(1):1509429.

19 Takyi SA, Amponsah O, Asibey MO, Ayambire RA. An overview of Ghana's educational system and its implication for educational equity. Int J Leader Educ. 2019:1-26

20 Nortey DA. Barriers to social participation for the deaf and hard of hearing in Ghana. Bergen, Norway: The University of Bergen; 2009.

21 Boadi F. Parents' perception on the education of the deaf-the perspective of parents of chil- dren with deafness at Ashanti school for the deaf, Jamasi, Ghana. 2017.

22 Senayah EA, Mprah WK, Opoku MP, Edusei AK, Torgbenu EL. The accessibility of health services to young deaf adolescents in Ghana. Int J Health Plann Manage. 2019;34(1):e63445.

23 Ganle JK, Otupiri E, Obeng B, Edusie AK, Ankomah A, Adanu R. Challenges women with disability face in accessing and using maternal healthcare services in Ghana: a qualitative study. PLoS One. 2016;11(6):e0158361.

24 Kwasi Ofosu D. Assessing the spatial distribution of health facilities in the Eastern Region of Ghana. 2012.

25 Kankam KS, Owusu I, Dogbe JA, Opoku VK. Challenges of screening and early detection of hearing impairment among children in some selected hospitals in Kumasi Metropolis College of Health Sciences: University of Science and Technology. 2017.

26 Jatto ME, Ogunkeyede SA, Adeyemo AA, Adeagbo K, Saiki O. Mothers' perspectives of newborn hearing screening programme. Ghana Med J. 2018;52(3):158-62.

27 Baroch KA. Universal newborn hearing screening: fine-tuning the process. Curr Opin Otolaryngol Head Neck Surg. 2003;11(6):424-7.

28 Hyde ML. Newborn hearing screening programs: overview. J Otolaryngol. 2005;34(2): S70.

29 Bezuidenhout J, Khoza-Shangase K, De Maayer T, Strehlau R. Universal newborn hearing screening in public healthcare in South Africa: challenges to implementation. S Afr J Child Health. 2018;12(4):159-63.

30 Emmett SD, Francis HW. The socioeconomic impact of hearing loss in U.S. adults. Otol Neurotol. 2015;36(3):545.

31 Agyire-Tettey EE, Cobbina M, Hamenoo ES. Academic challenges of students with hearing impairment (SHIs) in Ghana. Disability CBR Inclusive Dev. 2017;28(3):127-50. 
32 Swanepoel DW, Louw B, Hugo R. A novel service delivery model for infant hearing screening in developing countries: un modelo novedoso para la prestación de servicios de tamiz auditivo infantil en países en desarrollo. Int J Audiol. 2007;46(6):321-7.

33 Lovett RE, Kitterick PT, Hewitt CE, Summerfield AQ. Bilateral or unilateral cochlear implantation for deaf children: an observational study. Arch Dis Child. 2010;95(2):107-12.

34 Kanji A, Khoza-Shangase K. Objective hearing screening measures: an exploration of a suitable combination for risk-based newborn hearing screening. J Am Acad Audiol. 2018; 29(6):495-502.
35 Shearer AE, Smith RJ. Genetics: advances in genetic testing for deafness. Curr Opin Pediatr. 2012;24(6):679.

36 Schade G, Kothe C, Ruge G, Hess M, Meyer CG. [Non-invasive screening for GJB2 mutations in buccal smears for the diagnosis of inherited hearing impairment]. Laryngorhinootologie. 2003 Jun;82(6):397-401.

37 Schrauwen I, Sommen M, Corneveaux JJ, Reiman RA, Hackett NJ, Claes C, et al. A sensitive and specific diagnostic test for hearing loss using a microdroplet PCR-based approach and next generation sequencing. Am J Med Genet A. 2013;161A(1):145-52.
38 Tayoun AN, Mason-Suares H, Frisella AL, Bowser M, Duffy E, Mahanta L, et al. Targeted droplet-digital PCR as a tool for novel deletion discovery at the DFNB1 locus. Hum $\mathrm{Mu}$ tat. 2016;37(1):119-26.

39 Thompson DC, McPhillips H, Davis RL, Lieu TL, Homer CJ, Helfand M. Universal newborn hearing screening: summary of evidence. JAMA. 2001;286(16):2000-10.

40 Kennedy C, McCann D, Campbell MJ, Kimm L, Thornton R. Universal newborn screening for permanent childhood hearing impairment: an 8-year follow-up of a controlled trial. Lancet. 2005;366(9486):660-2. 